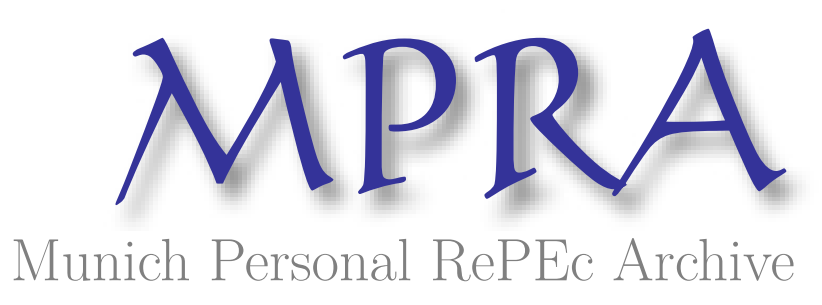

\title{
Migration, Social Security, and Economic Growth
}

Chen, Hung-Ju and Fang, I-Hsiang

2011

Online at https://mpra.ub.uni-muenchen.de/30251/

MPRA Paper No. 30251, posted 18 Apr 2011 12:47 UTC 


\title{
Migration, Social Security, and Economic Growth
}

\author{
Hung-Ju Chen* and I-Hsiang Fang ${ }^{+}$
}

\begin{abstract}
This paper studies the effect of population aging on economic performance in an overlapping-generations model with international migration. Fertility is endogenized so that immigrants and natives can have different fertility rates. Fertility is an important determinant to the tax burden of social security since it affects the quantity and quality of future tax payers. We find that introducing immigrants into the economy can reduce the tax burden of social security. If life expectancy (or the replacement ratio) is high enough, the growth rate of GDP per worker for an economy with international migration will be higher than for a closed economy. Regarding migration policies, our numerical results indicate that economic growth rate of GDP per worker will first decrease then increase as the flow of immigrants increases. Increasing the quality of immigrants will enhance economic growth.
\end{abstract}

Keywords: Economic growth; Fertility; Migration; Social security.

JEL Classification: F22, H55, O15.

\footnotetext{
* Corresponding author: Department of Economics, National Taiwan University, 21 Hsu-Chow Road, Taipei 100, Taiwan. Tel: 886-2-23519641 ext. 535. Fax: 886-2-23511826. E-mail: hjc@ntu.edu.tw.

+ Department of Economics, National Taiwan University, 21 Hsu-Chow Road, Taipei 100, Taiwan. Fax: 886-2-23511826. E-mail: r95323036@ntu.edu.tw.

We thank Jang-Ting Guo, Chen-Min Hsu, Min-Chung Hsu, Ching-Sheng Mao and participants of the 2009 Far East and South Asia Meeting of the Econometric Society and the 2010 CEANA Annual Meeting at Atlanta for their comments and suggestions. The first author would like to acknowledge the financial support provided by the Program for Globalization Studies at the Institute for Advanced Studies in Humanities, National Taiwan University (grant number: 99R018). The usual disclaimer applies.
} 


\section{INTRODUCTION}

Over the past century longevity has steadily increased in countries which have experienced economic growth. The upward trend of life expectancy in Canada, France, Japan, the United Kingdom and the U.S.A. during the period from 1980 to 2005 is presented in Figure 1a. One implication of longevity growth is that more resources must be devoted to supporting the elderly, and governments have often raised social security expenditures. Figure $1 \mathrm{~b}$ shows that the ratio of pension expenditure to GDP increased along with life expectancy in Canada, France, Japan, United Kingdom and U.S.A. over the period from 1980 to 2005 . $^{1}$

However, for most industrialized countries a decline in mortality is accompanied by a reduction in fertility over the course of development. The graying of many countries' populations has led many to worry about the future tax burden of social security. In short, the concern is that expenditures on old-age entitlements will continue to grow even as there are fewer young people available to contribute to the tax base.

There is a huge amount of literature devoted to the increasing social security burden caused by aging populations and possible solutions to this problem. These studies can be classified into two categories. The first line of research focuses on the sustainability of a pay-as-you-go (PAYG) system or on possible reforms to the social security system. The interaction of public investment in education, social security and growth is investigated by Kaganovich and Zilcha (1999) and Pecchenino and Pollard (2002). Based on a two-sector growth model, Zhang et al. (2001) compare the effects of mortality decline on long-run growth under funded and unfunded social security schemes. Recently, Groezen et al. (2003) and Fenge and Meier (2005) suggest that the burden of social security can be mitigated by using child allowances. With child allowances, the cost of raising children

\footnotetext{
1 Data source for Figures 1a and 1b: World Development Indicator, World Bank.
} 
becomes lower and parents will have stronger incentives to have more children. ${ }^{2}$

The second category of previous research considers the problem of increasing social security burden in an economy with international migration. This research line demonstrates that introducing immigrants can alleviate the increasing burden of social security for developed countries. Razin and Sadka (1999) show that even introducing lowskilled immigrants who are often beneficiaries of the welfare state into an economy can be beneficial to all income and all age groups. With a dynamic set-up, adult immigrants share the burden of social security with natives upon their migration into the host country. Although these immigrants will create a new welfare burden in the future, the burden will be shared by newly introduced immigrants as long as the economy is ever-lasting. By using the data from Current Population Survey (CPS) and Public Use Microdata Sample (PUMS), Lee and Miller (2000) project the fiscal impact of immigrants and their descendents. They find that the net present value contributed by an immigrant is always positive to the Old-Age, Survivors, and Disability Insurance (OASDI).

In this paper, we follow the second line of research to revisit the issue of an increasing social security burden in an economy with international migration. Besides examining the impact of introducing immigrants on the tax burden of a social security program, we also explore immigration's effects on key macroeconomic variables such as fertility, educational investment and economic growth. There are two major differences between this paper and existing research. First, while previous literature tends to treat fertility as an exogenous variable, fertility decisions are endogenized in this paper. ${ }^{3}$ It is now well-known that parents' decisions about fertility and the educational investments

\footnotetext{
2 However, this view is challenged by Mochida (2005) who argues that when uncertain lifetime is incorporated into the model, introducing child allowances does not necessarily increase fertility because it may induce a higher tax rate. With lower after-tax income and increasing life expectancy, adults may choose to work more and have fewer children in order to save more for their post-retirement consumption.

3 For example, Razin and Sadka (1999) and Doi et al. (2006) develop models with exogenous fertility rate to study the immigration issue for a host country.
} 
of their offspring are interdependent (Becker et al., 1990). ${ }^{4}$ Ehrlich and Lui (1991) demonstrate that if old agents are dependent on their offspring for material support, a decline in the mortality will raise parents' expected rate of investment in the human capital of their children and induce a corresponding reduction in fertility (the qualityquantity trade-off of children). The increase in the educational investment will in turn raise the long-run growth rate.

Second, we assume that the level of immigrants' human capital can be different from that of natives. Different levels of human capital cause immigrants and natives to make different choices about fertility and investment in their children's education. This change in human capital accumulation will then affect economic growth. Furthermore, fertility matters when considering an economy with heterogeneous agents, because it will also affect the future population structure and labor force. Both population structure and labor force are important determinants of the burden of social security.

We develop an overlapping-generations model of social security within which adults make decisions about consumption, fertility and investment in their children's education. In order to compare the impact of longevity in an economy with international migration with that in a closed economy, we first consider a simple, closed economy with a PAYG social security program. ${ }^{5}$ We show that a balancedgrowth-path (BGP) equilibrium exists in such an economy. An increase in life expectancy will increase the tax rate necessary for social security and reduce after-tax

\footnotetext{
4 A wealth of studies exists on the trade-off of fertility and educational investments of children. Among all, see de la Croix and Doepke (2003, 2004).

5 An economy with social security program and endogenous fertility is also studied by Zhang et al. (2003) and Zhang and Zhang (2003). However, in their studies, social security payments are treated as endogenous variables. The impact of choices of fertility and educational investment on the future social security payments are taken into consideration when parents make their decisions on the quality and quantity of children. In this paper, we follow Kaganovich and Zilcha (1999) and Groezen et al. (2003) by assuming that social security payment is treated as an exogenous variable when adults make optimal decisions.
} 
income. Reduced after-tax income will cause adults to have fewer children (income effect). But the lower after-tax wage rate will also reduce the time cost of raising children and will motivate adults to have more children (substitution effect). We find that the income effect will dominate the substitution effect and an increase in life expectancy will reduce fertility and investment in children's education. This will slow economic growth. On the other hand, longer life expectancy will induce more savings which increases economic growth. If life expectancy is high enough, the former effect will dominate the latter, and increased life expectancy will retard economic growth. We also find that an increase in social security payments will raise fertility and decrease educational expenditure if the degree of altruism is sufficiently low. Hence, under this condition an increase in the social security payment will lower economic growth.

Next, we consider an economy with international immigrants. In order to study the impact of migration policy regarding the quality of immigrants, we assume that immigrants possess a different level of human capital from natives. Our consideration of the heterogeneity among immigrants and natives is closely related to Storesletten (2000). A life-cycle model is developed by Storesletten (2000) to study if a reform of immigration policy can reduce the social security problem caused by the aging of the baby boom generation. He emphasized the characteristics of immigrants by assuming that immigrants are differentiated in age at the time of immigration and by their legal status. In his study, however, fertility and investment in children's education are not endogenous.

The existence of heterogeneous agents makes the model more complicated, so we simulate the model to quantify the effects of migration policy. We find that introducing low-skilled immigrants into the economy can reduce the social security tax rate since immigrants have higher fertility. A migration policy which allows the amount of 
immigrants whose human capital level is $94 \%$ of natives to be $2 \%$ of the population of natives in every period can lower the social security tax rate by $1.83 \%$ in the long run. If life expectancy (or the replacement ratio) is high enough, the growth rate of GDP per worker for an economy with migration will be higher than for a closed economy, provided that the gap of human capital between immigrants and natives is not large and the flow of immigrants is small.

Comparing the numerical results under endogenous-fertility and exogenousfertility models, we find that there will be biased estimation for the effects of life expectancy on fertility, social security tax rate and economic growth if one does not consider the endogenous change in fertility. The benefits brought by the immigration policy would be exaggerated for an ageing economy if fertility is not endogenized. We also study the impact of migration policies by changing the quantity and quality of immigrants. Our numerical results show that the economic growth rate will first decrease and then increase as more workers are allowed to migrate into the host country. On the other hand, increasing the quality of immigrants will enhance economic growth.

The remainder of this paper is organized as follows. In the next section we describe the basic settings of our model in a closed economy with a PAYG social security scheme. In Section 3, we develop an economy with international migration. In Section 4, we carry out numerical analysis to determine the effects of longevity, social security payments and migration policies on economic performance. The conclusions drawn from this study are presented in the final section.

\section{THE MODEL}

As a benchmark, we first examine the effects of social security in a closed economy comprised of homogeneous agents. We consider an infinite-horizon, discrete time 
overlapping-generations model within which agents live for three periods - childhood, adulthood (parenting) and old age. Agents always survive from childhood to adulthood, but their survival from adulthood to old age is uncertain. Each period covers approximately 30 years.

All decisions are made in adulthood, with adults deciding how many children they will have, how much to invest in their children's education, how much to consume, and how much they should save for their old age. When making such decisions, these adults face an uncertain probability $(p \in(0,1))$ of survival from adulthood to old age. There is a PAYG social security system implemented in this economy. In each period, the government levies a tax on adult wage income and transfers the tax revenue to the surviving old agents. Old agents do not work and consume their savings from the previous period, the returns from mutual funds, and social security benefits.

\subsection{Households}

Children born in period $t$ spend all of their time accumulating additional human capital. The human capital accumulation function depends on the educational investment made by their parents $\left(e_{t}\right)$ and parental human capital $\left(h_{t}\right)$, and is given by:

$$
h_{t+1}=B e_{t}^{\alpha} h_{t}^{1-\alpha},
$$

where $B>0$ represents the productivity of human capital accumulation and $\alpha \in(0,1)$ is the elasticity of children's human capital with respect to educational investment. ${ }^{6}$ We assume that the human capital accumulation function displays diminishing returns to scale in educational investments and constant returns to scale in parental human capital and educational investments in order to generate endogenous growth.

Following de la Croix and Doepke (2003), we assume that adults in period $t$ care

\footnotetext{
6 The Cobb-Douglas formation of the human capital accumulation function has been widely used in the literature on human capital; see, for example, Glomm and Ravikumar (1992).
} 
about the number of children $\left(n_{t}\right)$, their children's human capital $\left(h_{t+1}\right)$, their adult consumption $\left(c_{t}\right)$, and their old age consumption $\left(d_{t+1}\right)$. The expected lifetime utility function, which is identical for all adults, is defined as:

$$
U_{t}=\ln c_{t}+p \ln d_{t+1}+\sigma \ln n_{t} h_{t+1},
$$

where the parameter $\sigma>0$ reflects the degree of altruism amongst parents, and $p$ represents the probability that adults will survive to old age.

In each period, agents are endowed with one unit of time. They spend $l_{t}$ units of time on work to earn wages $\left(w_{t}\right)$ and the rest of time on raising children. We assume that each child consumes a fixed fraction $(q \in(0,1))$ of their parent's unit of time. Hence, the time constraint for adults is:

$$
l_{t}+q n_{t}=1
$$

Adults pay income tax with rate $\tau_{t}$ to the government and spend the after-tax income on consumption, investments in children's education, and savings $\left(s_{t}\right)$. The budget constraint for adults is:

$$
c_{t}+s_{t}+e_{t} n_{t}=\left(1-\tau_{t}\right) w_{t} l_{t} h_{t} .
$$

Following Yarri (1965) and Blanchard (1985), we assume that each adult's savings are deposited into mutual funds, which are invested in the capital market. Let $\left(1+r_{t+1}\right)$ denote the gross rate of return in the capital market; then the gross rate of return for those surviving to old age is:

$$
1+\rho_{t+1}=\frac{1+r_{t+1}}{p}
$$

The budget constraint for an old agent is therefore:

$$
d_{t+1}=\left(1+\rho_{t+1}\right) s_{t}+M_{t+1},
$$

where $M_{t+1}$ denotes the social security transfer in period $t+1$. Combining Eqs. (4) and (5) gives us the inter-temporal budget constraint: 


$$
c_{t}+\frac{d_{t+1}}{1+\rho_{t+1}}+e_{t} n_{t}=\left(1-\tau_{t}\right) w_{t} l_{t} h_{t}+\frac{M_{t+1}}{1+\rho_{t+1}} .
$$

Government taxes labor incomes to finance social security. Let $N_{t}$ denote the adult population in period $t$. The budget constraint for the government in period $t+1$ is:

$$
p N_{t} M_{t+1}=\tau_{t+1} w_{t+1} N_{t+1} l_{t+1} h_{t+1} .
$$

\subsection{Production}

Using physical capital $\left(K_{t}\right)$ and effective labor $\left(L_{t}=N_{t} l_{t} h_{t}\right)$, output $\left(Y_{t}\right)$ is produced by the following production function:

$$
Y_{t}=A K_{t}^{\theta} L_{t}^{1-\theta}
$$

where $A>0$ represents the total factor productivity and $\theta \in(0,1)$ is the share of physical capital income to the output.

Assuming perfectly competitive factor markets, the gross rate of the return on physical capital and the real wage rates are: ${ }^{7}$

$$
\begin{gathered}
1+r_{t+1}=A \theta K_{t+1}^{\theta-1} L_{t+1}^{1-\theta}, \\
w_{t}=A(1-\theta) K_{t}^{\theta} L_{t}^{-\theta} .
\end{gathered}
$$

Let $k_{t}=K_{t} / N_{t}$ denote the physical capital per worker. Then the output per worker $\left(y_{t}=Y_{t} / N_{t}\right)$ can be expressed by

$$
y_{t}=A k_{t}^{\theta}\left(l_{t} h_{t}\right)^{1-\theta} .
$$

\subsection{The Economy}

We are now able to define the equilibrium of the economy. Given the probability of survival ( $p$ ), the initial values of physical and human capital $\left\{K_{1}, h_{1}\right\}$ and the initial

\footnotetext{
7 We assume that physical capital completely depreciates after one period (30 years).
} 
value of population $N_{1}$, an equilibrium comprises of sequences of $\left\{K_{t}, h_{t}, N_{t}\right\}$, the factor prices and tax rate $\left\{r_{t}, w_{t}, \tau_{t}\right\}$ and households' decision rules $\left\{c_{t}, d_{t+1}, s_{t}, e_{t}\right.$, $\left.n_{t}\right\}$ such that:

1. Given $\left\{r_{t+1}, w_{t}\right\}$, households will make their decisions by maximizing their utility subject to budget constraints;

2. Firms choose $K_{t}$ and $L_{t}$ to maximize profits;

3. Markets clear;

4. Government runs the public pension system as a PAYG-scheme with the balanced budget constraint (Eq. (7) holds).

Adults will maximize Eq. (2), subject to Eqs. (1), (3) and (6). The optimal choices of $c_{t}, d_{t+1}, n_{t}$ and $e_{t}$ are:

$$
\begin{gathered}
c_{t}=\frac{\left(1-\tau_{t}\right) w_{t} h_{t}}{1+p+\sigma}+\frac{M_{t+1}}{(1+p+\sigma)\left(1+\rho_{t+1}\right)}, \\
d_{t+1}=p\left(1+\rho_{t+1}\right) c_{t}, \\
n_{t}=\frac{\sigma(1-\alpha)}{q(1+p+\sigma)}+\frac{\sigma(1-\alpha) M_{t+1}}{q\left(1-\tau_{t}\right)(1+p+\sigma)\left(1+\rho_{t+1}\right) w_{t} h_{t}}, \\
e_{t}=\frac{\alpha q\left(1-\tau_{t}\right) w_{t} h_{t}}{1-\alpha} .
\end{gathered}
$$

The capital market clearing condition implies that:

$$
K_{t+1}=N_{t} s_{t}
$$

The replacement ratio $(a)$ which is considered as a policy parameter is defined as the ratio of social security payment to the current wage income. ${ }^{8}$ That is:

$$
a=\frac{M_{t}}{w_{t} l_{t} h_{t}} .
$$

Combining Eqs. (7) and (17), we can derive that:

$$
\tau_{t+1}=\frac{p a N_{t}}{N_{t+1}}=\frac{p a}{n_{t}} .
$$

The same definition of social security benefits is used by Pecchenino and Pollard (2002). 
Eq. (18) shows that the tax rate needs to be adjusted in every period in order to keep the amount of social security benefit to be proportional to the adults' wage income. It also indicates that the higher fertility rate in the current period can help mitigate the tax burden for the social security in the next period.

Combining Eqs. (8), (9), (10) and (16), we can express the social security payments as:

$$
M_{t+1}=\frac{(1-\theta)\left(1+r_{t+1}\right) \tau_{t+1} s_{t}}{p \theta}
$$

Substituting Eq. (19) into Eqs. (5) and (12)-(14), the optimal decisions on savings and fertility are:

$$
\begin{gathered}
s_{t}=\frac{p \theta\left(1-\tau_{t}\right) w_{t} h_{t}}{\theta(1+p+\sigma)+\tau_{t+1}(1-\theta)(1+\sigma)}, \\
n_{t}=\frac{\sigma(1-\alpha)\left[\theta+\tau_{t+1}(1-\theta)\right]}{q\left[\theta(1+p+\sigma)+\tau_{t+1}(1-\theta)(1+\sigma)\right]} .
\end{gathered}
$$

In Appendix 1, we show that fertility is constant over time. Then Eqs. (3) and (18) indicate that labor input and tax rate are also constant. That is, $n_{t}=n, l_{t}=l, \tau_{t}=\tau$ for all $t$. In the following proposition, we prove that a unique BGP equilibrium exists in the economy.

Proposition 1. For a closed economy with homogeneous agents, there exists a unique BGP equilibrium. Furthermore, along the BGP , the growth factor is:

$$
g^{*}=\left\{\frac{[A q(1-\tau)(1-\theta)]^{\alpha}(p \theta)^{\alpha \theta}(1-\alpha)^{-\alpha} l^{-\alpha \theta}}{\left(B \alpha^{\alpha}\right)^{\theta-1} \sigma^{\alpha \theta}[\tau(1-\theta)+\theta]^{\alpha \theta}}\right\}^{\frac{1}{1-\theta(1-\alpha)}} .
$$

Proof: See Appendix 1.

We concentrate our study on the BGP equilibrium. Define $\phi_{t}=\frac{e_{t}}{w_{t} l_{t} h_{t}}$ to represent the ratio of educational investment per child to labor income. Using Eqs. (3) and (15), we can derive a function $\phi_{t}$ that remains constant over time: 


$$
\phi_{t}=\frac{\alpha q(1-\tau)}{(1-\alpha)(1-q n)}=\phi
$$

In the following Proposition, we examine the impacts of social security reform (that is, changes in the replacement ratio) on the fertility rate, the ratio of educational expenditure to labor income, and the growth factor.

Proposition 2. A rise in the replacement ratio will increase fertility. Furthermore, it will reduce the ratio of educational expenditure per child to labor income and the growth factor if $\sigma<\theta /(1-\theta)$.

\section{Proof: $\quad$ See Appendix 2.}

If the government raises the replacement ratio, the social security tax rate will be higher (Eq. (18)). The increase in the tax burden of social security will cause an income effect and a substitution effect. The lower after-tax labor income will motivate adults to work more and have fewer children (income effect). It will also reduce the educational investment. However, due to the lower after-tax wage rate, the opportunity cost of raising children become lower and adults will work less, have more children (substitution effect) and spend less on each child's education. As the replacement ratio increases, the substitution effect will dominate income effect and parents will have more children and invest less on children's education. ${ }^{9}$

Since parents spend less time on work, labor income will be lower. Because both the educational investment and labor income will decrease, the impact of an increase in the replacement ratio on the ratio educational expenditure to labor income depends on which factor dominates. If the degree of altruism among parents is low enough (such that $\sigma<\theta /(1-\theta)$ ), then parents do not care their children that much and the decrease in educational investment dominates the decrease in labor income and the

\footnotetext{
9 Our result is different from Zhang and Zhang (2004) since we do not consider bequests. If bequests are included in the model, an increase in the replacement ratio will have ambiguous impacts on fertility.
} 
ratio of education expenditure per child to labor income will become lower. The lower educational investment will slow the accumulation of human capital. Thus, an increase in the replacement ratio will reduce the rate of economic growth.

Next, we consider the effects of life expectancy on economic performance.

Proposition 3. An increase in life expectancy will reduce both fertility and the ratio of education expenditure per child to labor income. Moreover, an increase in life expectancy will slow economic growth if life expectancy is higher than the critical value $\tilde{p}$, where $\theta^{2}(1-\tau(\tilde{p}))=\tau(\tilde{p})[(1-\theta) \tau(\tilde{p})+\theta]$.

Proof: $\quad$ See Appendix 3.

An increase in life expectancy will increase the incentive for adults to save. Moreover, when life expectancy increases, the social security tax must increase to finance the increasing social security expenditure. The income effect caused by the increasing tax rate will dominate the substitution effect and fertility will decrease. Because of the increase in the incentive to save and the decrease in after-tax income, parents will invest less in each child's education and the ratio of educational expenditure to labor income will decrease. This will retard economic growth. On the other hand, savings themselves are beneficial to physical capital accumulation and therefore growth. The impact of life expectancy on growth depends on which effect dominates. If life expectancy is high enough, the effect of lower human capital accumulation will dominate the effect of higher physical capital accumulation due to the diminishing returns of physical capital. Then an increase in life expectancy will lower the economic growth rate. In Appendix 3, we show that this critical value of life expectancy $\tilde{p}$ is such that $\theta^{2}(1-\tau(\tilde{p}))=\tau(\tilde{p})[(1-\theta) \tau(\tilde{p})+\theta]$. 
Using parameter values calibrated in the next section, the implications of Proposition 3 are shown in Figure 2. When life expectancy increases from 0.2 to 1 , the tax rate will increase while fertility and the ratio of educational investment to labor income will decrease. Furthermore, as life expectancy increases, the growth rate will first increase and then decrease.

\section{INTERNATIONAL MIGRATION}

In this section, we consider an economy with international migration. We assume that before period one, the economy, comprised by homogenous agents with human capital $h_{t}^{1}$, is closed and moves along the BGP. In order to incorporate the difference in productivity between immigrants and natives in our model, we allow the level of human capital of immigrants to be different from natives in a closed economy. In period one, the economy opens for adult immigrants with human capital $h_{t}^{2}=\delta h_{t}^{1}$ and $\delta>0$. Note that the immigrants can be low-skilled or high-skilled workers depending on $\delta<1$ or $\delta>1$.

Let $N_{t}^{1}$ and $N_{t}^{H, 2}$ respectively denote the native adult population of type 1 and 2 agents. Then $N_{t}^{H}=N_{t}^{1}+N_{t}^{H, 2}$ represent the total adult population of natives in the host country. In each period, there will $N_{t}^{F, 2}$ foreign adults with human capital $h_{t}^{2}$ migrate into the host country. We assume that $N_{t}^{F, 2}=\mu N_{t}^{H}$ with $\mu \in(0,1)$. Then the adult population of type-2 agents migration occurs is $N_{t}^{2}=N_{t}^{H, 2}+N_{t}^{F, 2}$ and the total adult population after migration is $N_{t}=N_{t}^{1}+N_{t}^{2}$. The dynamics of the adult population for any $t>1$ is governed by:

$$
N_{t+1}=N_{t}^{1} n_{t}^{1}+N_{t}^{2} n_{t}^{2}+\mu N_{t+1}^{H}
$$




$$
=(1+\mu)\left(N_{t}^{1} n_{t}^{1}+N_{t}^{2} n_{t}^{2}\right) .
$$

We use $\Omega_{t}^{1}$ and $\Omega_{t}^{2}$ to respectively denote the respective ratios of type- 1 and 2 workers to the total adult population in period. Hence, $\Omega_{t}^{1}+\Omega_{t}^{2}=1$. The dynamics of respective ratios of type- 1 and 2 workers to the total population of workers follow:

$$
\Omega_{t+1}^{1}=\frac{\Omega_{t}^{1} n_{t}^{1}}{(1+\mu)\left(\Omega_{t}^{1} n_{t}^{1}+\Omega_{t}^{2} n_{t}^{2}\right)}, \quad \Omega_{t+1}^{2}=1-\Omega_{t+1}^{1} .
$$

Let $c_{t}^{i}, d_{t+1}^{i}, n_{t}^{i}$ and $e_{t}^{i}$ represent adult consumption, old age consumption, fertility and educational investment for type- $i$ workers. For each type of adults, they will maximize Eq. (2), subject to Eqs. (1), (3) and (6) based on their human capital. Given the human capital of each type agents $\left(h_{t}^{i}\right)$, the optimal decisions of $c_{t}^{i}, d_{t+1}^{i}, n_{t}^{i}$ and $e_{t}^{i}$ are given by Eqs. (12)-(15). Substituting Eq. (15) into Eq. (1), we can compute the level of human capital of the children for each type of agents as:

$$
\begin{gathered}
h_{t+1}^{1}=B\left(\frac{\alpha q\left(1-\tau_{t}\right) w_{t}}{1-\alpha}\right)^{\alpha} h_{t}^{1}, \\
h_{t+1}^{2}=B\left(\frac{\alpha q\left(1-\tau_{t}\right) w_{t} \delta h_{t}^{1}}{1-\alpha}\right)^{\alpha}\left(\delta h_{t}^{1}\right)^{1-\alpha}=\delta h_{t+1}^{1} .
\end{gathered}
$$

Therefore, the level of human capital of children with foreign parents will equal the level of human capital of immigrants in the next period. This implies that for any period $t \geq 1$, there are two types of agents with different levels human capital $\left(h_{t}^{i}\right.$, $i=1,2$ ). We assume that children of immigrants, born after their parents immigrated, are regarded as natives. Thus, the adult population of type- 2 agents is composed by natives with foreign ancestors and immigrants.

The average human capital in period $t$ is: 


$$
H_{t}=\Omega_{t}^{1} h_{t}^{1}+\Omega_{t}^{2} h_{t}^{2} .
$$

Let $l_{t}^{i}$ denote working time for type- $i$ workers. Then the effective labor in period $t$ is:

$$
L_{t}=N_{t}\left(\Omega_{t}^{1} h_{t}^{1} l_{t}^{1}+\Omega_{t}^{2} h_{t}^{2} l_{t}^{2}\right) .
$$

The capital market clearing condition is:

$$
K_{t+1}=N_{t}^{1} s_{t}^{1}+N_{t}^{2} s_{t}^{2}
$$

The factor prices are represented by Eqs. (9) and (10). All surviving old agents will receive the same social security payments proportional to the average wage income. That is:

$$
M_{t+1}=a w_{t+1}\left(\Omega_{t+1}^{1} h_{t+1}^{1} l_{t+1}^{1}+\Omega_{t+1}^{2} h_{t+1}^{2} l_{t+1}^{2}\right)
$$

The balanced budget constraint for the government is:

$$
p N_{t} M_{t+1}=\tau_{t+1} w_{t+1} N_{t+1} L_{t+1} .
$$

Eq. (28) together with Eq. (29) determine the tax rate:

$$
\tau_{t+1}=\frac{p a}{(1+\mu)\left(\Omega_{t}^{1} n_{t}^{1}+\Omega_{t}^{2} n_{t}^{2}\right)} .
$$

The optimal fertility choices for type- 1 and 2 adults can be solved by using Eqs. (5), (9), (10), (12)-(14), (27) and (29):

$$
\begin{gathered}
n_{t}^{1}=\frac{\sigma(1-\alpha)\left[\theta(1+p+\sigma)+(1-\theta)(1+\sigma) \tau_{t+1}+p(1-\theta) \tau_{t+1}\left(\Omega_{t}^{1}+\delta \Omega_{t}^{2}\right)\right]}{q(1+p+\sigma)\left[\theta(1+p+\sigma)+(1-\theta)(1+\sigma) \tau_{t+1}\right]} \\
n_{t}^{2}=\frac{\sigma(1-\alpha)\left\{\delta\left[\theta(1+p+\sigma)+(1-\theta)(1+\sigma) \tau_{t+1}\right]+p(1-\theta) \tau_{t+1}\left(\Omega_{t}^{1}+\delta \Omega_{t}^{2}\right)\right\}}{q \delta(1+p+\sigma)\left[\theta(1+p+\sigma)+(1-\theta)(1+\sigma) \tau_{t+1}\right]} .
\end{gathered}
$$

Notice that

$$
n_{t}^{1}-n_{t}^{2}=\frac{-p \sigma(1-\alpha)(1-\theta)(1-\delta) \tau_{t+1}\left(\Omega_{t}^{1}+\delta \Omega_{t}^{2}\right)}{q \delta(1+p+\sigma)\left[\theta(1+p+\sigma)+(1-\theta)(1+\sigma) \tau_{t+1}\right]}
$$


Eq. (33) implies that $n_{t}^{1} \leq n_{t}^{2}$ if and only if $\delta \leq 1$ and vice versa. Because for parents with low human capital, the time cost of raising children is lower, then they will tend to have more children than those with high human capital

\section{NUMERICAL EXPERIMENT}

Due to the complexity of the model, in this section we simulate our model in order to quantify the influence of migration on economic performance. Before proceeding with our computational work, we calibrate the parameters used in the model to match U.S. data. The calibration of parameter values is based upon economic performance along the BGP under a closed economy. All of the following calibrated parameter values are referred to as benchmark model parameter values.

\subsection{Calibration}

We set the share of physical capital income to the output $(\theta)$ to 0.3 . The parameters $A$ and $B$ are respectively set at 14.998 and 2.272 so that the annual growth rate is $2 \%$ and the initial ratio of physical capital to human capital is 1 (Kendrick, 1976). Haveman and Wolfe (1995) suggest that raising a child will cost approximately 15 percent of parents' time endowment. Hence, $q$ is assigned to 0.15 . The total fertility rate of U.S. in recent years is about 2 children per woman, so we choose the degree of altruism $\sigma$ used in the utility function to be 0.35 in order to make the representative agent have about 1 child per person. In 2005, life expectancy is 78 years in U.S. Since one period equals 30 years in this model, we set $p=0.6$ to replicate the actual circumstance. For human capital accumulation function, we follow Chen (2005) to set $\alpha$ equal to 0.2 .

The remaining parameter to be calibrated for is the replacement ratio. Based on Pecchenino and Pollard (2002), we set the replacement ratio ( $a$ ) to 0.4. Given these 
benchmark model parameter values, the annual growth rate is $2 \%$, the fertility rate is 1.070 , the ratio of educational investment to labor income is $3.466 \%$ and the tax rate is $22.422 \%$ along the BGP equilibrium for a closed economy.

When an economy opens for international migration, there are two important parameters regarding the quality and quantity of immigrants to be considered. Regarding the quality of immigrants, we follow the literature of human capital and use years of schooling to measure the level of human capital. Comparing the years of education of natives and immigrants of USA, Borjas (1993) finds that on average, immigrants have 11.859 years of schooling which is 0.8 years fewer than natives. This implies that immigrants are low-skilled workers and we set the parameter $\delta$ to $11.859 /(11.859+0.8)=94 \%$. Regarding the quantity of immigrants, we first assign $\mu=2 \%$ so that the number of migrants is only a small fraction of the native adult population. The assumption that the economy opens for international migration in the first period implies that $\Omega_{1}^{1}=\frac{1}{1+\mu}=0.98$. Given that our main goal is to study the influence of the migration, we will conduct sensitivity analysis on $\delta$ and $\mu$.

\subsection{Results}

We begin our analysis by comparing the effects of life expectancy on long-run (tenth period) economic performance for an economy with and without international migration. ${ }^{10}$ Details of the long-run impact of migration on average fertility, average ratio of educational expenditure to labor income, tax rate and the annual growth rate are presented in Table 1, with columns 2 and 3 providing the simulation results under benchmark model parameter values. Comparing these two columns, we find that a small amount of immigrants can have significant effects since introducing immigration

\footnotetext{
${ }^{10}$ In this paper, we do not consider the transitional dynamics and focus on the results in the long run.
} 
can lower the tax rate by $1.83 \%$ and fertility by $0.14 \%$ and increase the ratio of educational investment to labor income by $0.5 \%$. The growth rate is reduced by $0.11 \%$ due to the introduction of low-skilled immigrants.

$<$ Table 1 is inserted about here>

The effects of raising longevity from 0.2 (life expectancy is 66 years) to 1 (life expectancy is 90 years) on economic performance are shown in Figure 2. It shows that with an increase in longevity, the social security burden becomes heavier and the aftertax income decreases. Hence, adults will spend more time on work and both educational expenditure and fertility will fall. Comparing the tax rate in an economy with migration with that in a closed economy, we find that introducing immigration will lower the social security tax rate and the spread of the tax rate widens as the life expectancy goes up. Columns 4 and 5 of Table 1 display the effects for $p=1$ under two different economies. Table 1 shows that the gap between the tax rates under a closed economy and an economy with migration increases from $0.41 \%$ to $0.7 \%$ when $p$ increases from 0.6 to 1 .

$<$ Figure 2 is inserted about here>

For both economies, the economic growth will first increase then decrease as the life expectancy increases. Note that immigration changes the skill composition of the economy. Eq. (33) indicates that with the introducing of low-skilled immigrants, immigrants have higher fertility rate than natives. This implies that the proportion of type-2 workers who possess lower human capital to the total adult population will increase over time. Figure 2 shows that the annual growth rate in an economy with migration is lower than that in a closed economy when life expectancy is low due to the introduction of low-skilled immigrants. However, if life expectancy is high enough, the growth rate in an economy with migration will exceed than that in a closed 
economy because the introduction of immigrants can mitigate the social security tax burden and adults can invest more in their children's education.

Numerical Result 1. Introducing low-skilled immigrants can mitigate the tax burden of social security, with a larger effect as life expectancy increases. When life expectancy is low, the growth rate in an economy with migration is lower than that in a closed economy due to the low human capital of immigrants. However, the growth rate in an economy with migration will be higher if life expectancy is high enough, provided that the gap of human capital between immigrants and high-skilled natives is not too large, and the flow of immigrants is small.

Next, we consider the effects of changes in the replacement ratio. The results are shown in Figure 3. As the replacement ratio increases, the tax rate will increase while fertility will decrease as demonstrated in Proposition 2. Due to the quality-quantity trade-off in children, educational expenditure will decrease and this will in turn lower the growth rate. Comparing the economic performance of an economy with migration with a closed economy, we find that the introduction of immigrants can help reduce the tax burden, with a larger effect as the replacement ratio increases. The average fertility is lower and the average ratio of educational investment to labor income is higher in an economy with migration. The growth rate of an economy with migration is lower when the replacement ratio is small due to the lower level of immigrants' human capital. However, if the replacement ratio is large enough, the growth rate for an economy with migration will be higher because of higher educational investments. The last two columns of Table 1 reveal the effects for $a=0.9$ under a closed economy and an economy with migration. 
Numerical Result 2. Introducing low-skilled immigrants can mitigate the tax burden of social security, with a larger effect as the replacement ratio increases. If the gap in human capital between immigrants and natives is not too large and the flow of immigrants is small, the economic growth rate in an economy with migration will be higher than that in a closed economy when the replacement ratio is sufficiently high.

$<$ Figure 3 is inserted about here>

\section{3 Endogenous v.s. Exogenous Fertility}

To demonstrate the important role of endogenous fertility on the effect of social security burden and economic growth, Figures 4 and 5 present the results of exogenous fertility with varying life expectancy and replacement ratio, respectively. The exogenous fertility rates of type- 1 and type- 2 agents are set to equal the fertility rates under benchmark ( $p=0.6, a=0.4)$. The resulting fertility rate for type- 1 agents is 1.067 and for type-2 agents is 1.079 .

$<$ Figure 4 is inserted about here>

Recall that the Numerical Result 1 demonstrates that the average fertility decreases with an increase in the life expectancy in the endogenous-fertility model. Thus, when the life expectancy is lower than 0.6 , the endogenous-fertility model will generate higher average fertility as shown in Figure 4. This induces lower social security tax rate and a higher ratio of educational investment to labor income. Although the ratio of educational investment to labor income increases, the ratio of educational investment to human capital decreases because an increase in the labor force reduces the wage rate. Therefore, the economic growth rate is lower in the endogenous-fertility model. When life expectancy is higher than 0.6 , its effects on average fertility, social security tax rate and the ratio of educational investment to 
labor income in the endogenous- and exogenous-fertility models will be reversed. However, the economic growth rate is still lower in the endogenous-fertility model. This comparison implies that when studying the effects of migration policy, there will be biased estimation of its effects on fertility, tax rate and economic growth if fertility is not endogenized. Especially, the economic growth rate may be over-predicted and the benefits migration policy may be exaggerated.

$<$ Figure 5 is inserted about here $>$

Recall that the Numerical Result 2 demonstrates that the average fertility increases with an increase in the replacement ratio in the endogenous-fertility model. Thus, the endogenous-fertility model will generate lower average fertility when the replacement ratio is lower than 0.4 as shown in Figure 5. Then the social security tax rate will be higher and the ratio of educational investment to labor income and the economic growth rate will be lower. The situation will be reversed if the replacement ratio is larger than 0.4. Similarly, there will be biased estimation of the effects of replacement ratio on fertility, tax rate and economic growth if fertility is not endogenized.

\section{4 Migration Policy}

In the previous section we show that introducing immigrants can have macroeconomic effects. In this section, we examine the impact of migration policy by changing the quality and quantity of immigrants. We first increase $\mu$ from 0.02 to 0.18 to study how it affects the economic performance.

$<$ Figure 6 is inserted about here $>$

Figure $6 \mathrm{a}$ indicates that when the government introduces more immigrants into the economy (an increase in $\mu$ ), there will be more workers sharing the social security burden and the tax rate will become lower. Figure $6 \mathrm{~b}$ presents fertility and the ratio of 
educational investment to labor income for different types of agents in an economy with migration and for agents in a closed economy. With a higher after-tax wage rate, the opportunity cost of rearing children becomes higher, so for both types of agents the fertility rate declines and the ratio of educational expenditure to labor income increases with an increase in $\mu$. Thus, the average fertility will decrease while the average ratio of educational expenditure to labor income will increase.

Changes in $\mu$ will affect the economic growth through two channels. On one hand, the increase in $\mu$ will raise the proportion of educational investment to labor income. On the other hand, an increase in $\mu$ implies an increase in the proportion of low-skilled adults to the total adult population, and this lowers the average human capital. Our numerical results show that if $\mu$ is small, the latter will dominate the former and the economic growth rate will decrease with an increase in the flow of immigrants. However, the situation will be reversed is $\mu$ is sufficiently large.

Numerical Result 3. A rise in the flow of low-skilled immigrants will lower the social security tax rate. It will reduce the average fertility and raise the average ratio of educational expenditure to labor income. The relationship between economic growth rate and flow of immigrants exhibits a U-shape.

In our baseline model, we assume that immigrants have a lower level of human capital than natives. We now allow $\delta$ to vary from 0.5 to 1.3 to examine how the level of human capital of immigrations affects economic performance. The results are presented in Figure 7. Changes in $\delta$ will affect fertility in two ways. When immigrants (as well as the type-2 agents) are better-educated, they will choose to have fewer children (direct effect). However, changes in $\delta$ will also affect the fertility choice for type-1 agents as indicated by Eq. (31) (indirect effect). This is because as 
type-2 agents become better-educated, their labor income will increase and they will save more. Both investment and the average human capital will increase, so economic growth will increase. This will raise the future social security payments and the expected life-time income for type- 1 agents. Thus, the fertility for type- 1 agents will increase with an increase in $\delta$ as exhibited in Figure $7 \mathrm{~b}$.

Figure 7a shows that when $\delta<1$ (immigrants are low-skilled workers), the direct effect dominates the indirect effect and the average fertility decreases as $\delta$ increases. Hence, there will be fewer young people sharing the social security burden in the next generation, and the tax rate will increase with $\delta$. Because of lower after-tax income, the average ratio of educational investment to labor income will decrease. Although the decrease in educational expenditure will retard economic growth, more educated immigrants will raise average human capital and will increase economic growth. Our numerical exercise indicates that the economic growth will increase with $\delta$.

$<$ Figure 7 is inserted about here>

If immigrants are high-skilled workers $(\delta>1)$, an increase in $\delta$ will raise the average fertility and the average ratio of educational expenditure to labor income and will lower the tax rate. Both increases in $\phi$ and average human capital increase growth. Hence, economic growth will increase as $\delta$ increases.

Numerical Result 4. If immigrants are low-skilled workers, an increase in the level of human capital of immigrants will reduce the average fertility and the average ratio of educational investment to labor income and will increase the tax rate. The situation will be reversed if immigrants are high-skilled workers. However, no matter which type immigrants are, an increase in the level of human capital of immigrants tends to increase the economic growth rate. 


\subsection{Convergence of Human Capital}

In Section 3, we show that there always exist two types of agents and the ratio of human capital levels for agents of native dynasties to agents of immigrant dynasties remains constant forever. However, the estimation of Borjas (1994) indicates that it takes approximately 100 years for the human capital level of agents belonging to immigrant dynasties to converge to the level of agents belong to native dynasties. In order to capture the idea of the convergence of human capital, we now extend our basic model by assuming that human capital accumulation also depends on the average human capital. That is:

$$
h_{t+1}^{i}=B\left(e_{t}^{i}\right)^{\alpha} H_{t}^{\beta}\left(h_{t}^{i}\right)^{1-\alpha-\beta},
$$

where $\beta \in(0,1)$ is the elasticity of children's human capital with respect to the average human capital.

We assume that before period 1, the economy is closed and comprised by homogenous agents. We refer these agents and their descendants as the type-1 agents. At the beginning of period 1 , the economy opens for international migration and introduces immigrants possessing human capital level as a constant fraction $(\delta)$ of type-1 agents. Due to the setting of log-utility function, the first-order conditions of consumption, fertility and educational investment are the same as those in Section 3. Then the human capital of the children of natives and immigrants will be:

$$
\begin{gathered}
h_{2}^{1}=B\left(\frac{\alpha q\left(1-\tau_{1}\right) w_{1} h_{1}^{1}}{1-\alpha}\right)^{\alpha}\left(H_{1}\right)^{\beta}\left(h_{1}^{1}\right)^{1-\alpha-\beta} . \\
h_{2}^{2}=B\left(\frac{\alpha q\left(1-\tau_{1}\right) w_{1} \delta h_{1}^{1}}{1-\alpha}\right)^{\alpha}\left(H_{1}\right)^{\beta}\left(\delta h_{1}^{1}\right)^{1-\alpha-\beta}=\delta^{1-\beta} h_{2}^{1} .
\end{gathered}
$$

Besides, the immigrants in period 2 will possess human capital of the level of $\delta h_{2}^{1}$. Therefore, there will be three types of agents living in period 2: agents whose 
ancestors are natives in period 1 possess human capital $h_{2}^{1}$, agents whose ancestors are immigrants in period 1 possess human capital $\delta^{1-\beta} h_{2}^{1}$ and agents who just immigrate into the economy possess human capital $\delta h_{2}^{1}$.

As one can see, the types of agents will increase as time goes by. Comparing these results with those obtained in our basic model, the major difference is that in period $t$, there only exist two types of agents with human capital of $h_{t}^{1}$ and $\delta h_{t}^{1}$ in the basic model while there exist $(t+1)$ types of agents with human capital of $h_{t}^{1}$, $\delta^{(1-\beta)^{\mathrm{t}-1}} h_{t}^{1}, \ldots, \delta^{1-\beta} h_{t}^{1}$ and $\delta h_{t}^{1}$ in the current model. Our previous analysis has demonstrated that fertility decreases with an increase in the level of human capital. Thus, the average fertility will be lower in the current model than in our basic model if immigrants possess lower human capital than type- 1 agents (that is, $\delta<1$ ). ${ }^{11}$ If the purpose to introduce lower-human-capital immigrants into the economy is to increase future population to share the tax burden of social security, then it will cause a smaller reduction in tax in the current model than in the basic model due to the lower average fertility.

To examine the speed of convergence, notice that after 4 periods (approximate 120 years), there will be 5 types of agents with human capital of $h_{4}^{1}, \delta h_{4}^{1}, \delta^{1-\beta} h_{4}^{1}$, $\delta^{(1-\beta)^{2}} h_{4}^{1}$ and $\delta^{(1-\beta)^{3}} h_{4}^{1}$. Two important determinants to the speed of convergence of human capital of descendants of immigrants are $\delta$ and $\beta$. Note that we have calibrated $\delta$ to 0.94 . The empirical study finds that comparing with the elasticity of private educational investment, the elasticity of average human capital is relatively smaller. Based on the estimation of Card and Krueger (1996) and Krueger and Lindahl (2001), de la Croix and Doepke (2003) set $\beta$ to 0.1 to conduct numerical exercises. The ratio of human capital of the descendants of immigrants who moved into the country 120

\footnotetext{
${ }^{11}$ Because $\beta \in(0,1)$ and $\delta \in(0,1)$, then $\delta^{(1-\beta)^{\mathrm{t}-1}}>\delta^{(1-\beta)^{\mathrm{t}-2}}>\cdots>\delta$.
} 
years ago to the human capital of the descendants of natives is $\delta^{(1-\beta)^{3}}$. By assigning $\delta=0.94$ and $\beta=0.1$, this ratio equals 0.95 . It is easy to verify that the speed of convergence of human capital increases as $\delta$ or $\beta$ increases. $^{12}$

\section{CONCLUSIONS}

This study presents an analysis of the impact of introducing immigration on economic performance in an overlapping-generations model with uncertain lifetime and a social security system. Our analysis shows that introducing immigrants into the economy can help reduce the social security burden. If the gap in human capital between immigrants and natives is not too large and the flow of immigrants is small, the growth rate in an economy with migration will be higher than that in a closed economy when life expectancy (or the replacement ratio) is sufficiently high.

Concerning migration polices, we find that there is a U-shape relationship between the economic growth rate and the flow of immigrants. Although increasing the flow of immigrants can reduce the tax burden of social security, it is not necessary good for economic growth. On the other hand, increasing the quality of immigrants is beneficial for economic growth, but it raises the tax burden of social security if immigrants are low-skilled workers.

A few notes are worth discussing. First, throughout the paper, we focus on the effects of legal immigration. If we also consider illegal immigration into the analysis, then migration may help reduce the tax burden of social security even more. This is because illegal immigrants are not eligible for social security, but their children who are considered to be natives will participate in the social security program and need to share the burden of social security. Second, we use a simple three-period OLG model in this paper to study how immigration affects the burden of social security through the

\footnotetext{
12 For example, if $\beta$ increases to 0.3 , then $\delta^{(1-\beta)^{3}}$ will equal 0.98 .
} 
channel of fertility. It would be more interesting if we study this issue by extending the model to a life-cycle model with more periods of life (e.g., a period length of at most 5 years). A life-cycle model will allow us to study the effects of a particular immigration policy which allows certain ages and skills of workers to immigrate on the social security burden for the host country.

We conclude by suggesting two possible directions in which our model can be easily extended and applied. First, we assume that all immigrants can stay in the host country permanently. It would be interesting to extend the model to study the effects of temporary immigrants. Secondly, our model ignores the social costs of introducing immigrants such as cultural conflict. Adding such costs may reduce economic growth and social welfare. 


\section{REFERENCES}

Becker, G., Murphy, K., Tamura, R., 1990. Human capital, fertility and economic growth. Journal of Political Economy 98, 12-37.

Blanchard, O., 1985. Debt, deficits and finite horizons. Journal of Political Economy 93, 223-47.

Borjas, G.J., 1993. Immigration policy, national origin, and immigrants skills: a comparison of Canada and the United States. In: Card, D., Freeman, R. (Eds), Small Differences that Matter: Labor Markets and Income Maintenance in Canada and the United States, University of Chicago Press, pp.21-44.

Borjas, G.J., 1994. Long-run convergence of ethnic skill differentials: the children and grand-children of the great migration. Industrial and Labor Relations Review 47, 553-573.

Card, D. and Krueger, A.B., 1996. School resources and student outcomes: an overview of the literature and new evidence from North and South Carolina. Journal of Economic Perspectives 10, 31-50.

Chen, H.-J., 2005. Educational systems, growth and income distribution: a quantitative study. Journal of Development Economics 76, 325-353.

de la Croix, D., Doepke, M., 2003. Inequality and growth: why differential fertility matters. American Economic Review 93, 1091-113.

de la Croix, D., Doepke, M., 2004. Public versus private education: when differential fertility matters. Journal of Development Economics 73, 607-29.

Doi, J., Ikefuji, M., Mizushima, A., Mochida, M., 2006. Immigration, Aging, and Growth. Discussion Paper No. 143, Osaka University.

Ehrlich, I., Lui, F.T., 1991. Intergenerational trade, longevity and economic growth. Journal of Political Economy 99, 1029-59.

Fenge, R., Meier, V., 2005. Pensions and fertility incentives. Canadian Journal of Economics 38, 28-48.

Glomm, G., Ravikumar, B., 1992. Public versus private investment in human capital: endogenous growth and income inequality. Journal of Political Economy 100, 818-834.

Groezen, B., Leers, T., Meijdam, L., 2003. Social security and endogenous fertility: 
pensions and child allowances as Siamese twins. Journal of Public Economics 87, 233-251.

Haveman, R., Wolfe, B., 1995. The determinants of children's attainments: a review of methods and findings. Journal of Economic Literature 33, 1829-1878.

Kaganovich, M., Zilcha, I., 1999. Education, social security, and growth. Journal of Public Economics 71, 289-309.

Kendrick, J.W., 1976. The Formation and Stocks of Total Capital, New York: Columbia University Press.

Krueger, A.B. and Lindahl, M., 2001. Education and growth: why and for whom? Journal of Economic Literature 39, 1101-1136.

Lee, R., Miller T., 2000. Immigration, social security, and broader fiscal impacts. American Economic Review 90, 350-354.

Mochida, M., 2005. Child allowances, fertility, and uncertain lifetime. Discussion Paper 05-11, Osaka University.

Pecchenino, R.A., Pollard, P.S., 2002. Dependent children and aged pares: funding education and social security in an aging economy. Journal of Macroeconomics 24, 145-169.

Razin, A., Sadka, E., 1999. Migration and pension with international capital mobility. Journal of Public Economics 74, 141-15.

Storesleten, K., 2000. Sustaining fiscal policy through immigration. Journal of Political Economy, 108:300-323.

Yarri, M.E., 1965. Uncertain lifetime, life insurance and the theory of the consumer. Review of Economic Studies 32, 137-50.

Zhang, J., Zhang, J., 2003. Long-run effects of unfunded social security with earningsdependent benefits. Journal of Economic Dynamics and Control 28, 617-641.

Zhang, J., Zhang, J., Lee, R., 2003. Rising longevity, education, savings and growth. Journal of Development Economics 70, 83-101. 


\section{Appendix 1}

\section{Proof of Proposition 1}

We first prove that there exists a unique equilibrium. Substituting Eq. (18) into Eq. (21), we have:

$$
n_{t}=\frac{\sigma(1-\alpha)\left[\theta+\frac{p a}{n_{t}}(1-\theta)\right]}{q\left[\theta(1+p+\sigma)+\frac{p a}{n_{t}}(1-\theta)(1+\sigma)\right]}
$$

Let

$$
f\left(n_{t}\right)=q \theta(1+p+\sigma) n_{t}^{2}+[q p a(1-\theta)(1+\sigma)-\sigma \theta(1-\alpha)] n_{t}-p a \sigma(1-\alpha)(1-\theta) .
$$

The optimal solution(s) of fertility can be calculated by solving $f\left(n_{t}\right)=0$. Note that:

$$
\Delta=[q p a(1-\theta)(1+\sigma)-\sigma \theta(1-\alpha)]^{2}+4 q \theta(1+p+\sigma) p a \sigma(1-\alpha)(1-\theta)>0 .
$$

Since $f\left(n_{t}\right)$ is a quadratic function, $\Delta>0$ indicates that there exist two real solutions for $f\left(n_{t}\right)=0$. Furthermore, the product of these two solutions is negative. This implies that there exists a unique positive, constant solution of $n_{t}\left(n_{t}=n \forall t\right)$. Then from Eqs. (3) and (18), we know that labor input and the tax rate are also constant $\left(l_{t}=l, \tau_{t}=\tau \forall t\right)$. Substituting the constant fertility rate and tax rate into Eqs. (12), (13), (15), (19) and (20), we can calculate the unique solutions of $c_{t}, d_{t+1}$, $e_{t}, s_{t}$ and $M_{t+1}$.

We next show the existence of balanced growth path. Along the BGP equilibrium, $g^{*}=\frac{k_{t+1}}{k_{t}}=\frac{h_{t+1}}{h_{t}}$. That is, the ratio of $\left(\frac{k_{t}}{h_{t}}\right)$ is stationary along the BGP equilibrium.

Combining Eqs. (1), (10) and (15), we can derive:

$$
\frac{h_{t+1}}{h_{t}}=B\left[\frac{\alpha q A(1-\theta)(1-\tau) l^{-\theta}}{1-\alpha}\right]^{\alpha}\left(\frac{k_{t}}{h_{t}}\right)^{\alpha \theta}
$$

Combining Eqs. (10), (16), (20) and (21), we can calculate: 


$$
\frac{k_{t+1}}{k_{t}}=\frac{p \theta q A(1-\theta)(1-\tau) l^{-\theta}}{\sigma(1-\alpha)[(1-\theta) \tau+\theta]}\left(\frac{k_{t}}{h_{t}}\right)^{\theta-1} .
$$

Using the property that Eqs. (A2) and (A3) are equal, the stationary variable $\left(\frac{k_{t}}{h_{t}}\right)$ can be expressed as:

$$
\frac{k_{t}}{h_{t}}=\left\{\frac{p \theta[A q(1-\tau)(1-\theta)]^{1-\alpha} l^{\theta(\alpha-1)}}{B \sigma \alpha^{\alpha}(1-\alpha)^{1-\alpha}[(1-\theta) \tau+\theta]}\right\}^{\frac{1}{1-\theta(1-\alpha)}} .
$$

Substituting Eq. (A4) into Eq. (A2) gives us the growth factor:

$$
g^{*}=\left\{\frac{[A q(1-\tau)(1-\theta)]^{\alpha}(p \theta)^{\alpha \theta}(1-\alpha)^{-\alpha} l^{-\alpha \theta}}{\left(B \alpha^{\alpha}\right)^{\theta-1} \sigma^{\alpha \theta}[\tau(1-\theta)+\theta]^{\alpha \theta}}\right\}^{\frac{1}{1-\theta(1-\alpha)}} .
$$

QED. 


\section{Appendix 2}

\section{Proof of Proposition 2}

From Eq. (A1), we can derive the impact of the replacement ratio on fertility:

$$
\frac{\partial n}{\partial a}=\frac{\theta \sigma(1-\alpha)(1-\theta) \frac{p^{2}}{n}}{q[\theta(1+p+\sigma)+\tau(1-\theta)(1+\sigma)]^{2}+a \theta \sigma(1-\alpha)(1-\theta)\left(\frac{p}{n}\right)^{2}}>0 .
$$

From Eq. (22), we can derive the impact of the replacement ratio on $\phi$ :

$$
\frac{\partial \phi}{\partial a}=\alpha q \frac{(1-\tau) q \frac{\partial n}{\partial a}-(1-q n) \frac{\partial \tau}{\partial a}}{(1-\alpha)(1-q n)^{2}}
$$

Using Eqs. (18), (21) and (A6), we know that $(1-\tau) q \frac{\partial n}{\partial a}-(1-q n) \frac{\partial \tau}{\partial a}<0$ if

$$
\begin{array}{r}
{[\theta(1+p+\sigma)+\tau(1-\theta)(1+\sigma)][\theta(1+p+\alpha \sigma)+\tau(1-\theta)(1+\alpha \sigma)]} \\
>p \theta \sigma(1-\theta)\{(1-\theta)(1-\alpha)(1-\tau) .
\end{array}
$$

Note that the inequality (A7) holds if $\sigma<\frac{\theta}{1-\theta}$. Then according Eq. (A6), $\frac{\partial \phi}{\partial a}<0$ if $\sigma<\frac{\theta}{1-\theta}$

The derivative of the growth factor respect to the replacement ratio is:

$$
\frac{\partial g^{*}}{\partial a}=-\Gamma_{1}\left\{[\tau(1-\theta)+\theta]\left[(1-q n) \frac{\partial \tau}{\partial a}-\theta q(1-\tau) \frac{\partial n}{\partial a}\right]+\theta(1-\tau)(1-\theta)(1-q n) \frac{\partial \tau}{\partial a}\right\},
$$

where $\Gamma_{1}=\frac{\alpha}{1-\theta(1-\alpha)}\left\{\frac{[A q(1-\theta)]^{\alpha}(p \theta)^{\alpha \theta}(1-\tau)^{(1-\alpha)(\theta-1)} l^{-1-\alpha \theta+\theta(1-\alpha)}}{\left(B \alpha^{\alpha}\right)^{\theta-1}(1-\alpha)^{\alpha} \sigma^{\alpha \theta}[\tau(1-\theta)+\theta]^{1+\alpha \theta-\theta(1-\alpha)}}\right\}^{\frac{1}{1-\theta(1-\alpha)}}>0$.

Since $\theta \in(0,1)$, then $(1-q n) \frac{\partial \tau}{\partial a}>\theta q(1-\tau) \frac{\partial n}{\partial a}$ if the inequality (A7) holds.

Combining with the fact that $\frac{\partial \tau}{\partial a}>0$, we have that $\frac{\partial g^{*}}{\partial a}<0$ if $\sigma<\frac{\theta}{1-\theta}$.

QED. 


\section{Appendix 3}

\section{Proof of Proposition 3}

From Eq. (A1), we can derive the impact of $p$ on fertility:

$$
\frac{\partial n}{\partial p}=\frac{-\theta^{2} \sigma(1-\alpha)}{q[\theta(1+p+\sigma)+\tau(1-\theta)(1+\sigma)]^{2}+\theta \sigma(1-\alpha)(1-\theta) \frac{p^{2} a}{n^{2}}}<0
$$

This implies that $\frac{\partial \tau}{\partial p}=\frac{a}{n}-\frac{p a}{n^{2}} \frac{\partial n}{\partial p}>0$.

From Eq. (22), we can derive the impact of $p$ on $\phi$ :

$$
\frac{\partial \phi}{\partial p}=-\alpha q \frac{(1-q n) \frac{\partial \tau}{\partial p}-(1-\tau) q \frac{\partial n}{\partial p}}{(1-\alpha)(1-q n)^{2}}<0
$$

The partial derivative of the growth factor respect to the replacement ratio is:

$$
\frac{\partial g^{*}}{\partial p}=\Gamma_{2}\left(\Gamma_{3}+\Gamma_{4}\right)
$$

where

$$
\begin{aligned}
& \Gamma_{2}=\frac{\alpha}{1-\theta(1-\alpha)}\left\{\frac{[A q(1-\theta)]^{\alpha} p^{\alpha \theta-1+\theta(1-\alpha)} \theta^{\alpha \theta}(1-\tau)^{(1-\alpha)(\theta-1)} l^{-1-\alpha \theta+\theta(1-\alpha)}}{\left(B \alpha^{\alpha}\right)^{\theta-1}(1-\alpha)^{\alpha} \sigma^{\alpha \theta}[\tau(1-\theta)+\theta]^{1+\alpha \theta-\theta(1-\alpha)}}\right\}^{\frac{1}{1-\theta(1-\alpha)}}>0, \\
& \Gamma_{3}=(1-q n)\left\{\theta^{2}(1-\tau)-\tau[(1-\theta) \tau+\theta]\right\}, \\
& \Gamma_{4}=p \frac{\partial n}{\partial p}\left\{(1-q n) \frac{p a}{n^{2}}[(1-\theta) \tau+\theta]+\frac{p a}{n^{2}} \theta(1-\tau)(1-\theta)+\theta^{2} q(1-\tau)\right\}<0 .
\end{aligned}
$$

Note that $\Gamma_{3}<0$ if $\theta^{2}(1-\tau)<\tau[(1-\theta) \tau+\theta]$. Let $f_{1}(p)=\theta^{2}(1-\tau)$ and $f_{2}(p)=\tau[(1-\theta) \tau+\theta]$. Define $\tilde{p}$ such that $f_{1}(\tilde{p})=f_{2}(\tilde{p})$. Because $f_{1}(p)$ is a monotonically decreasing function in $p, f_{2}(p)$ is a monotonically increasing function in $p$ and $f_{1}(p=0)=\theta^{2}>f_{2}(p=0)=0$, then $f_{1}(p)<f_{2}(p)$ if $p>\tilde{p}$. Hence, $\frac{\partial g^{*}}{\partial p}<0$ if $p>\tilde{p}$.

QED. 
Table 1 Numerical results

\begin{tabular}{|c|c|c|c|c|c|c|}
\hline & \multicolumn{2}{|c|}{$p=0.6, a=0.4$} & \multicolumn{2}{|c|}{$p=1, a=0.4$} & \multicolumn{2}{|c|}{$p=0.6, a=0.9$} \\
\hline & Closed & Open & Closed & Open & Closed & Open \\
\hline$\overline{\mathrm{Av}}$ & 1.0704 & 1.0689 & 0.9997 & 0.9975 & 1.1416 & 1.1398 \\
\hline Avg. & 3.4656 & 3.4830 & 2.6465 & 61 & 2.3844 & 2.4222 \\
\hline & 22.4218 & 22.0122 & 40.0109 & 39.3141 & 47.3041 & 46.4499 \\
\hline Growth rate $(\%)$ & 2.0000 & 1.9978 & 1.8398 & 1.8435 & 1.5716 & 1.5798 \\
\hline
\end{tabular}




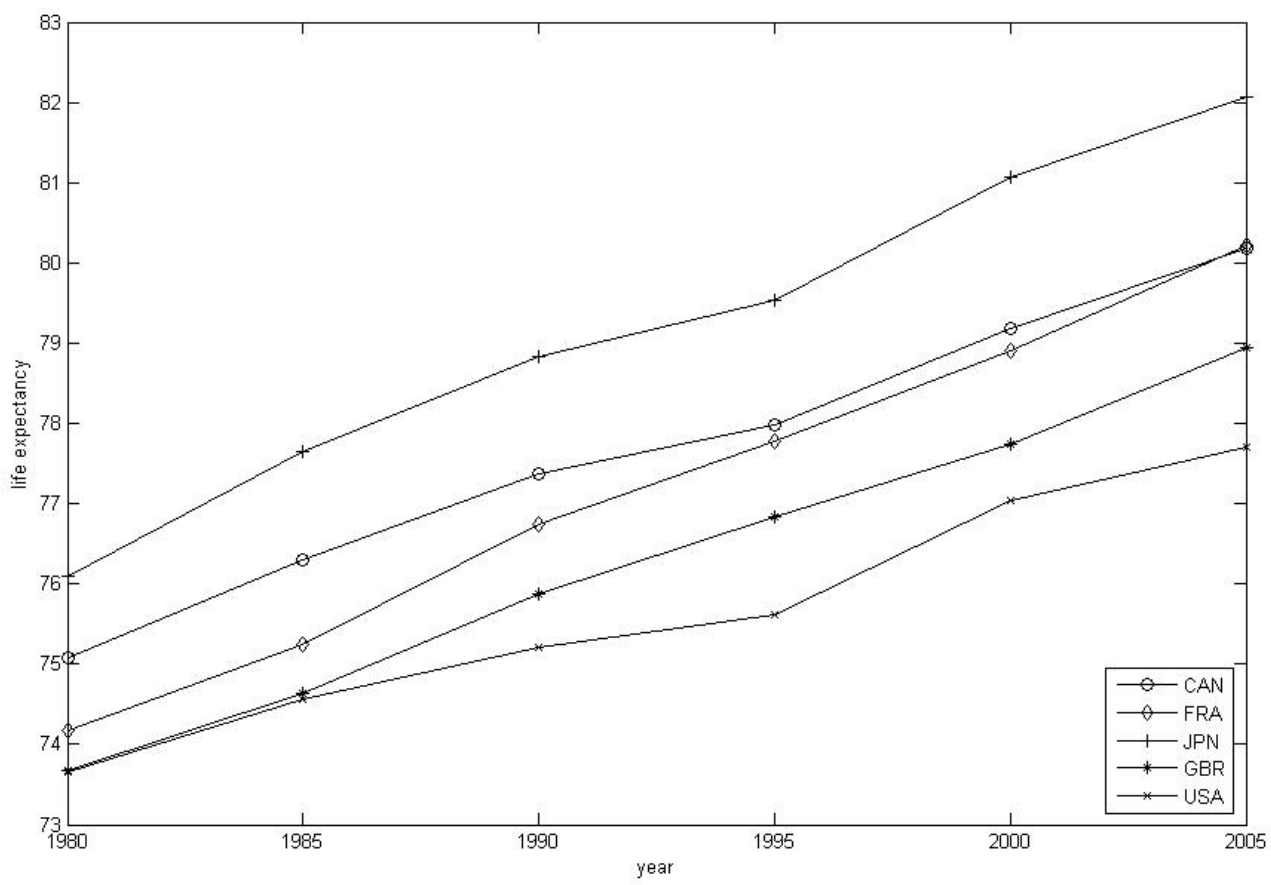

Figure la Life expectancy

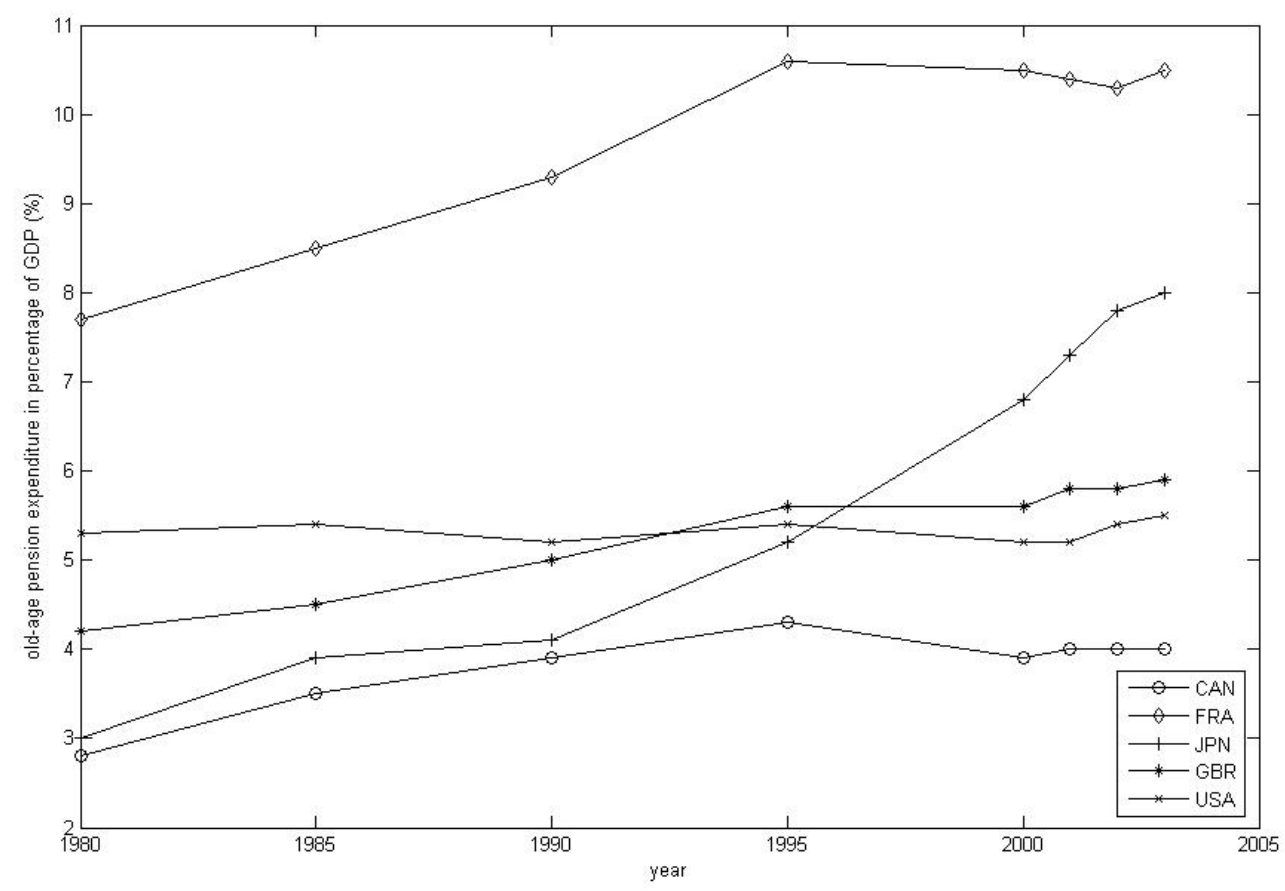

Figure $1 b$ The percentage of pension expenditure to GDP 

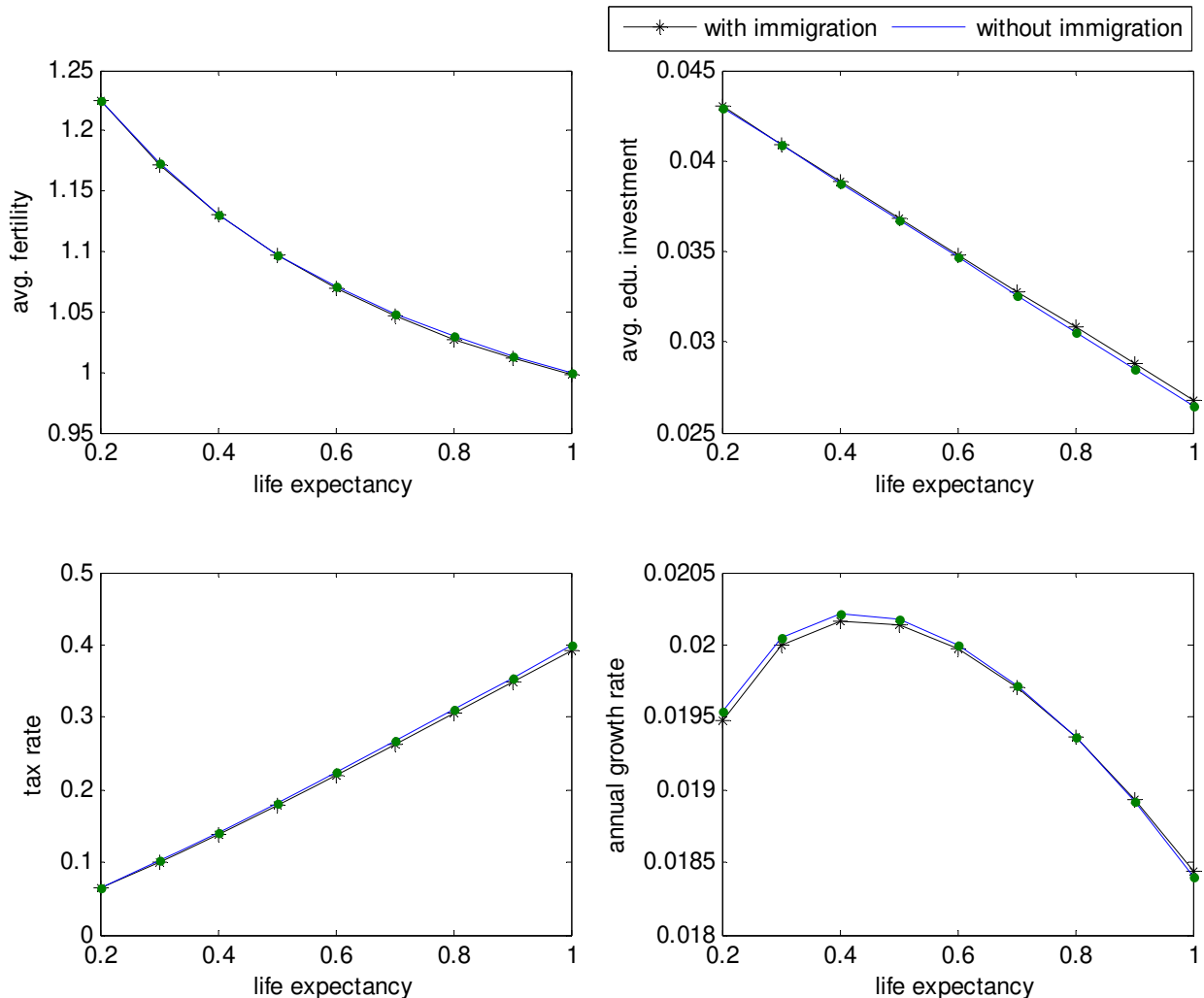

Figure 2 Effect of life expectancy on economic performance
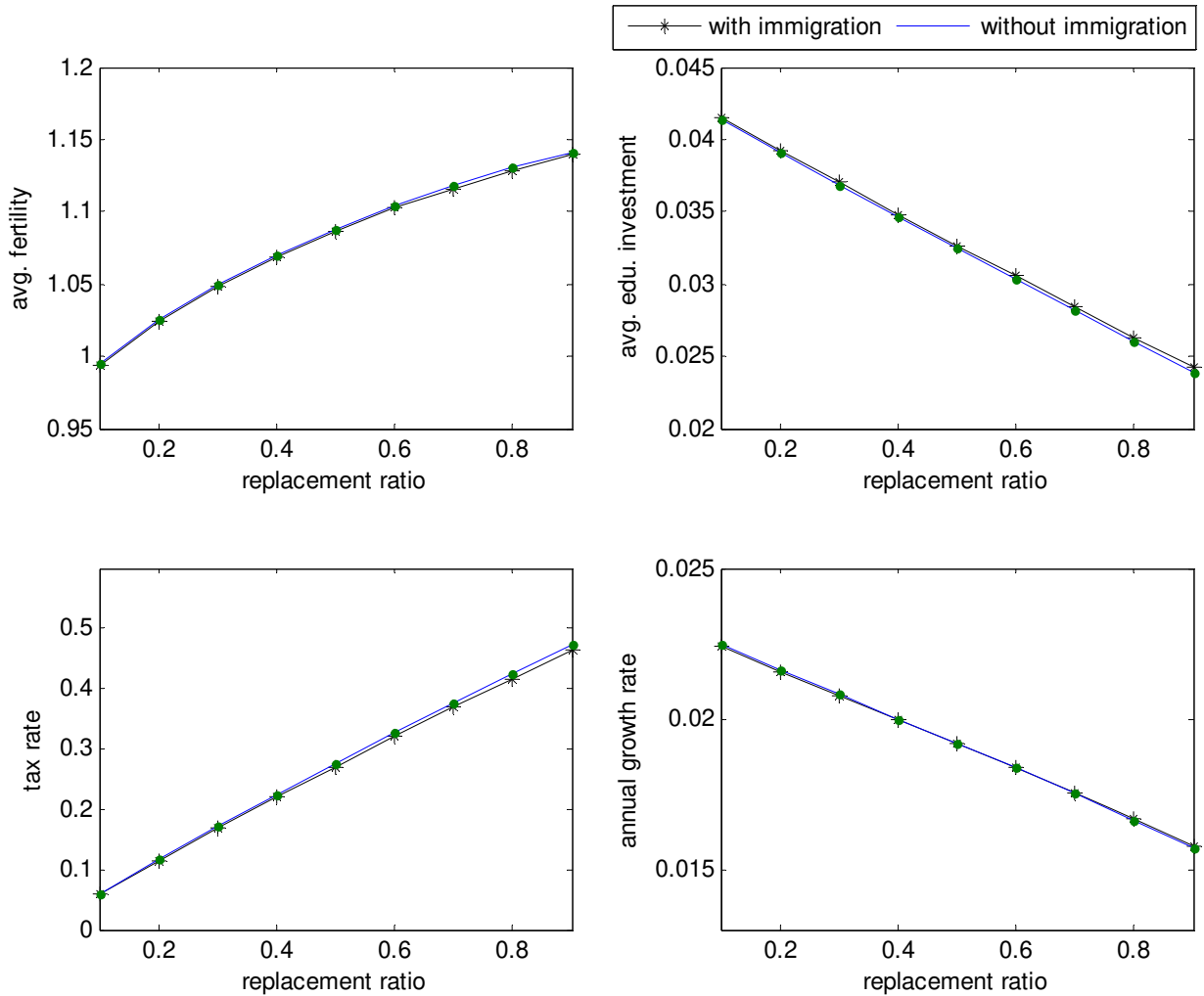

Figure 3 Effect of replacement ratio on economic performance 

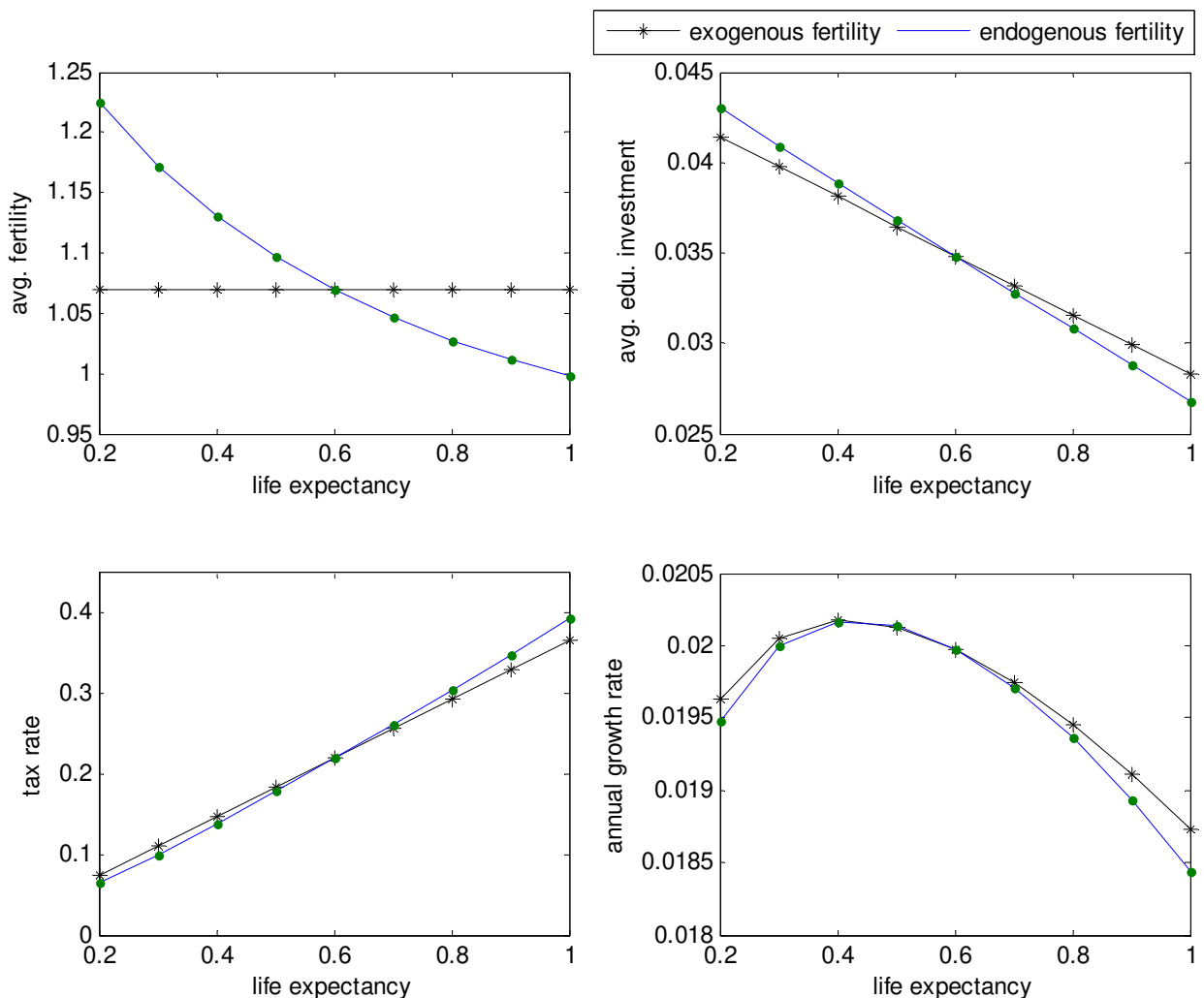

Figure 4 Effect of life expectancy for exogenous fertility and endogenous fertility
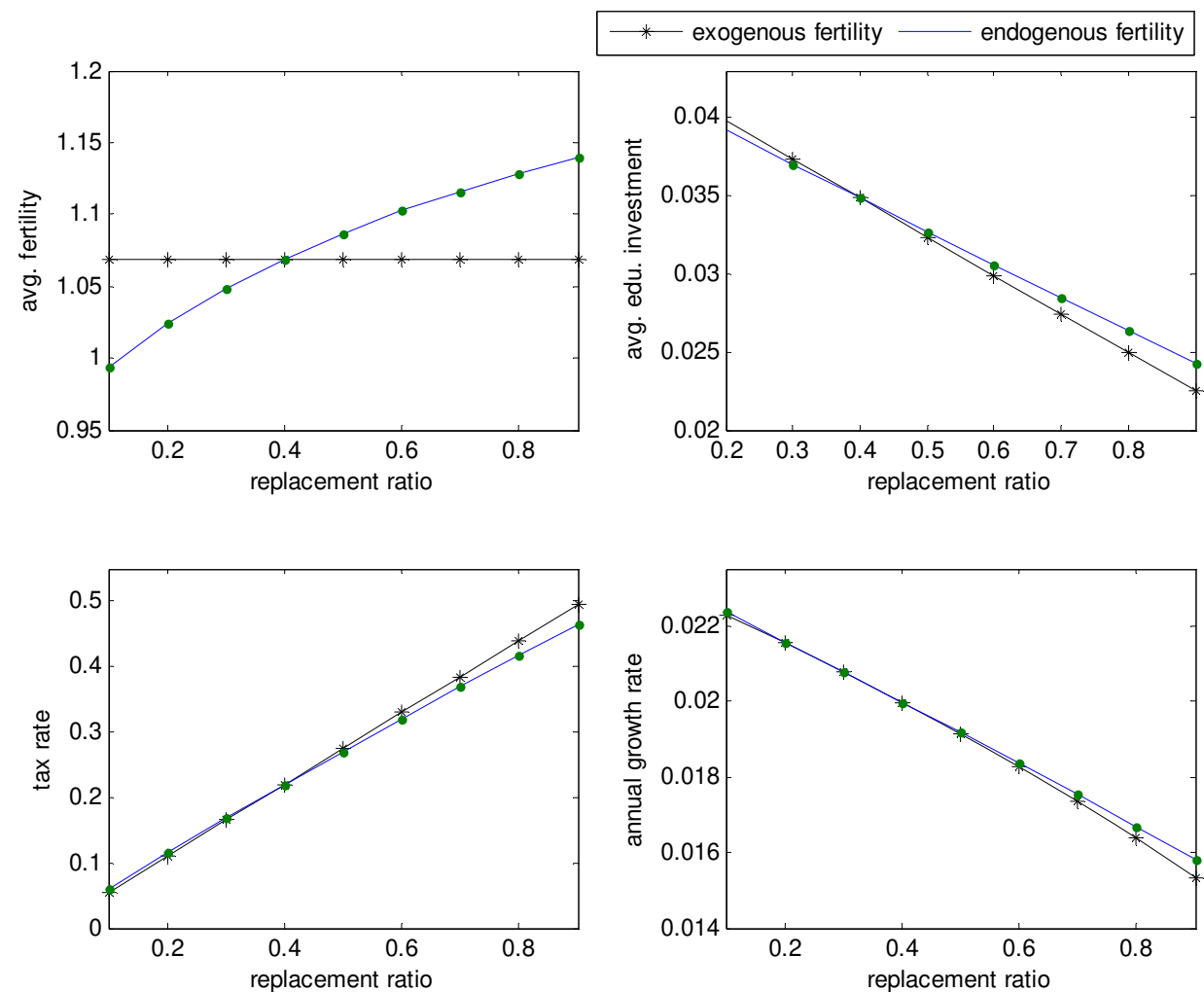

Figure 5 Effect of replacement ratio for exogenous fertility and endogenous fertility 

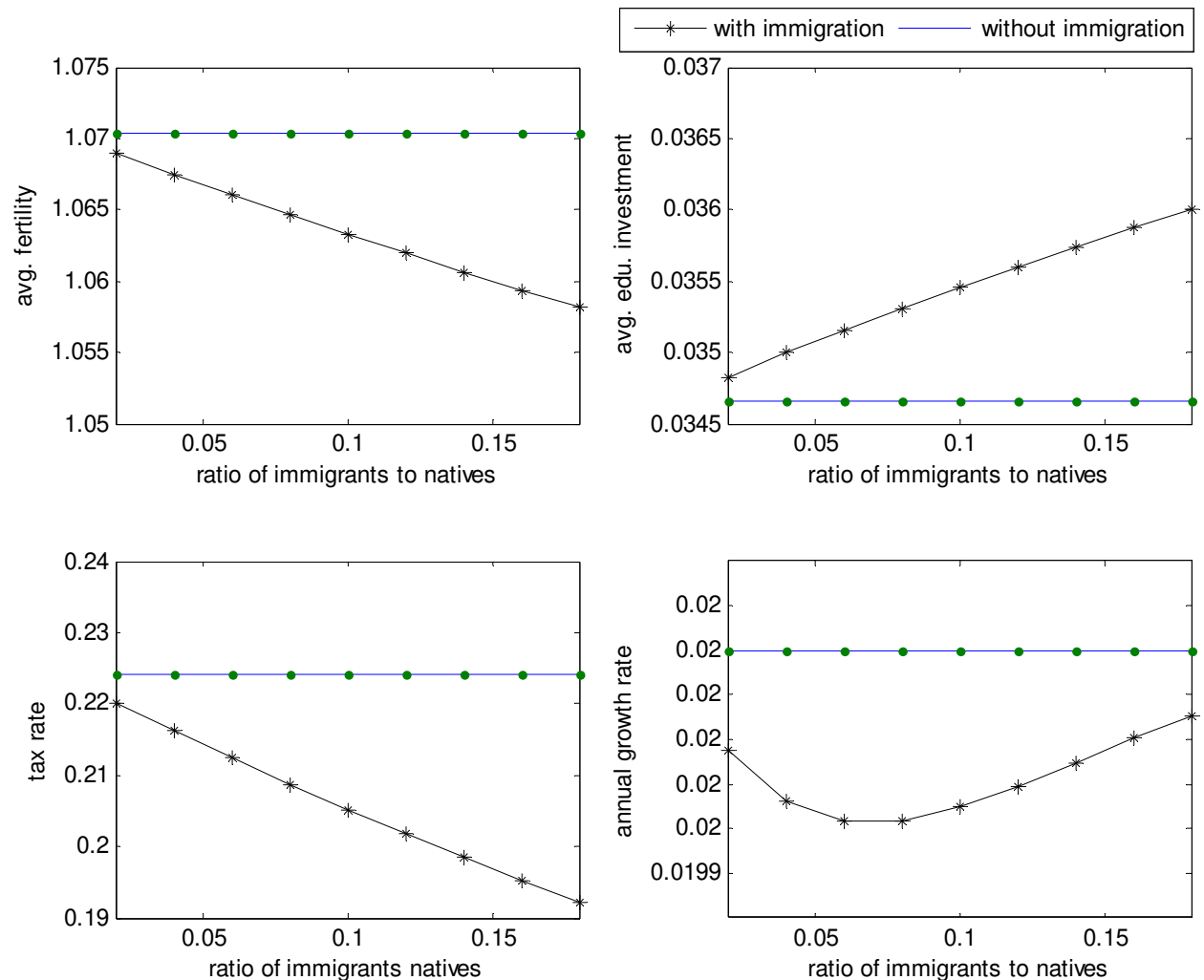

Figure 6a
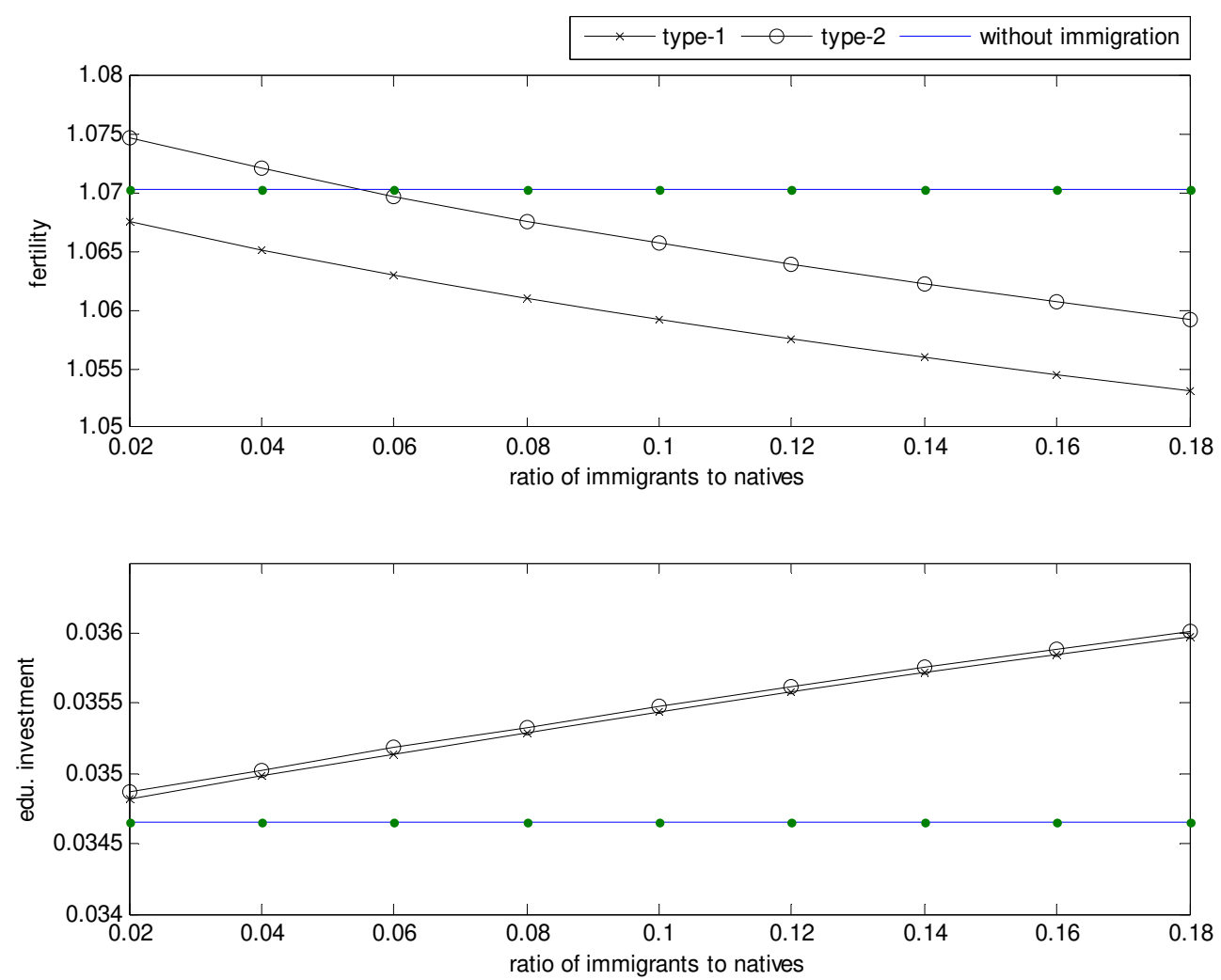

Figure $6 b$

Figure 6 Effect of the number of immigrants 

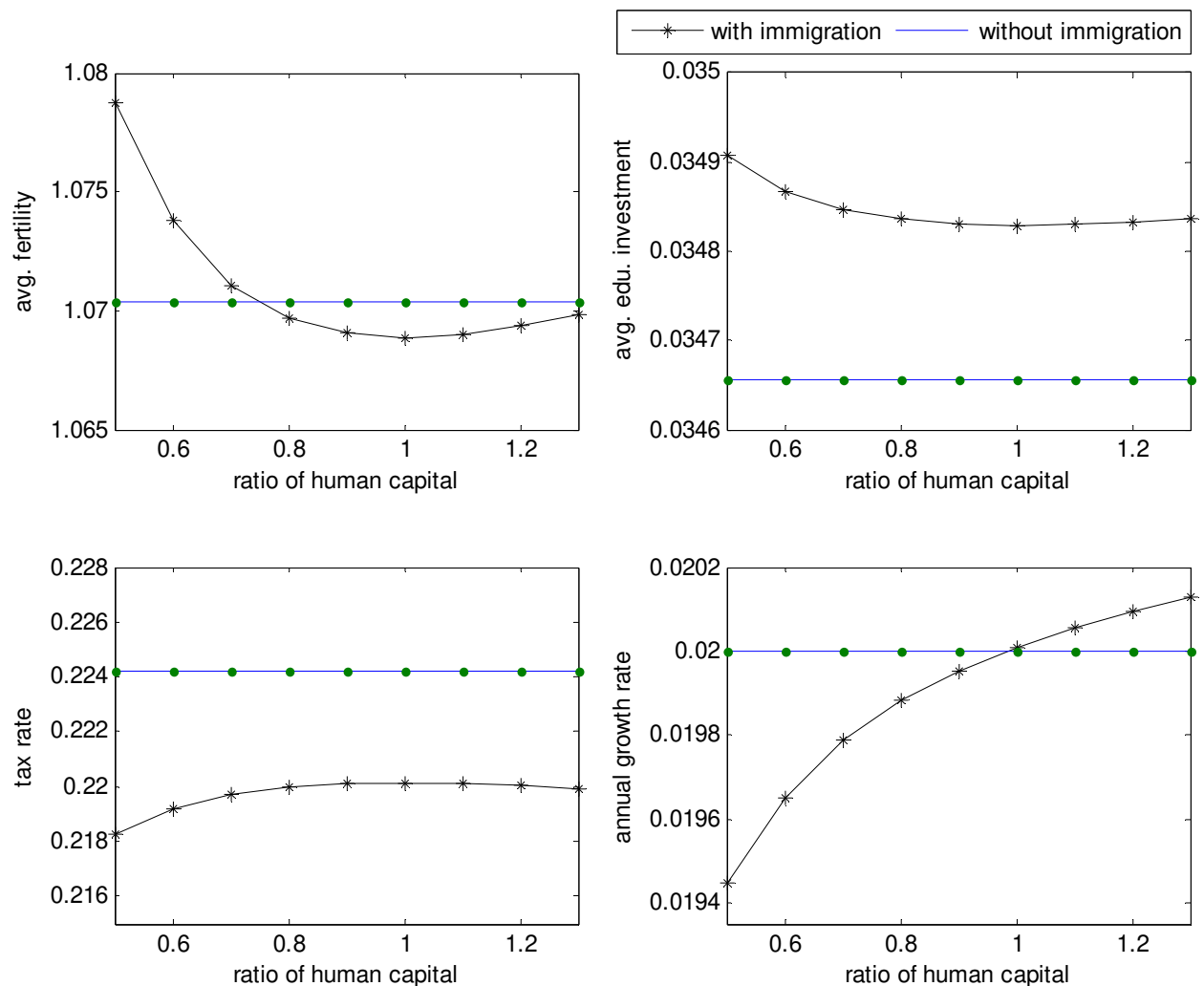

Figure $7 a$
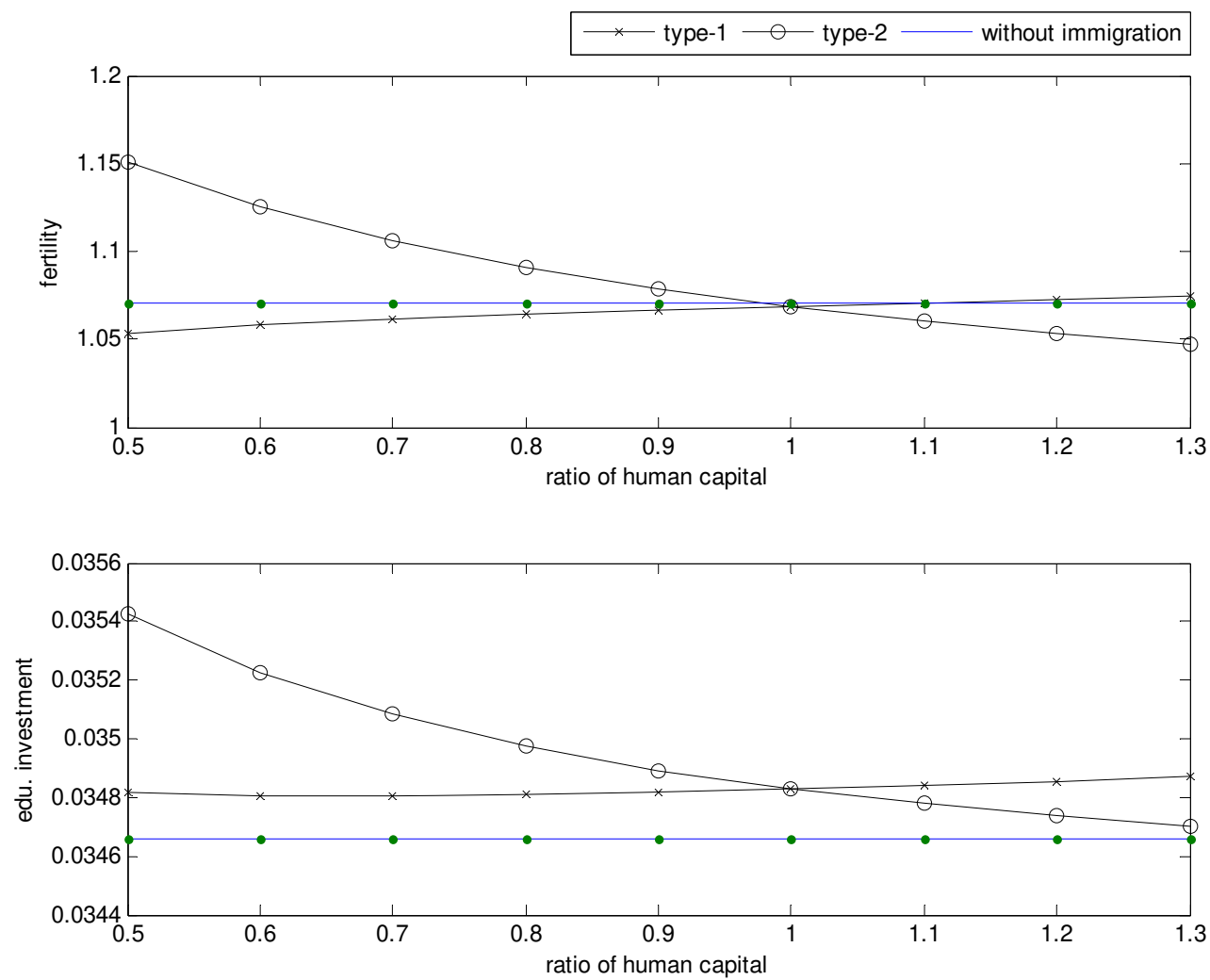

Figure $7 b$

Figure 7 Effect of immigrants' human capital 